\title{
Gun Control, the Right to Self- Defense, and Reasonable Beneficence to All
}

\author{
DUSTIN CRUMMETT \\ Ludwig Maximilian University of Munich
}

PHILIP SWENSON

College of William \& Mary

\begin{abstract}
One of the strongest arguments against the implementation of gun control measures is that such measures violate the right to self-defense or security against attack. The argument, defended by Michael Huemer and others, claims that even if a particular gun control measure has good results overall, it infringes, in a manner which is prima facie seriously wrong, the rights of those who end up being killed or significantly harmed due to their resultant inability to defend themselves. We claim that uncertainty on the part of the government about who will be harmed by a particular gun control measure underwrites a strong response to this argument. If gun control measures save lives on balance, then they may increase each person's chance of remaining safe relative to the information available to the government, even if they will cause some people to be harmed who otherwise would not have been. We draw on Caspar Hare's arguments for the claim that there are no conflicts between morality and reasonable beneficence to contend that this fact would vindicate gun control policies.
\end{abstract}

\section{Introduction}

Gun control involves, broadly speaking, state regulation of firearms. One important and much debated form of gun control involves preventing or making it harder for citizens, or certain groups of citizens, to obtain firearms, or certain kinds of firearms; when we speak of gun control, we will have this form

Contact: Dustin Crummett < $\underline{\text { dustin.crummett@gmail.com }>\text { and }}$ Philip Swenson $<$ pjswenson@wm.edu $\geq$ 
in mind. ${ }^{1}$ Such measures exist on a spectrum from more to less restrictive. For instance, a law making it illegal for children to buy sniper rifles is less restrictive than one making it illegal for any civilian to own any type of firearm. One of the strongest arguments against the implementation of fairly restrictive gun control measures involves the claim that such measures violate the right to self-defense, whose strength is itself derived from the very weighty right to physical security. The argument says that even if a particular gun control measure has good results overall, it infringes, in a manner which is prima facie seriously wrong, the rights of those who end up being killed or significantly harmed due to their resultant inability to defend themselves. We will argue that uncertainty on the part of the government about who will be harmed by a particular gun control measure underwrites a strong response to this argument. Our aim is not to provide a positive defense of any very restrictive gun control measure. For instance, it is compatible with our argument that such measures cost lives on balance, and are therefore inadvisable for consequentialist reasons. Our project is instead just to undermine the self-defense argument. Our aim is also not to evaluate the relative merits of different restrictive gun control measures, though our argument in Section 4 will imply that measures which avoid the self-defense objection will need to incorporate a certain exemption defended by David DeGrazia (2016), which is advisable on other grounds anyway.

A version of the argument is given by Michael Huemer, who claims that any very restrictive gun control measure can be justified only if it would save "many times as many lives as it cost" (2003: 317). This is supposed to be because such a policy violates the right of some to self-defense, and violating weighty rights is only justified when very great gains can be made by doing so. Similar arguments have been endorsed by (perhaps among others) Timothy Hall (2006), Deane Peter-Baker (2014), Timothy Hsiao (2015), and Lester H. Hunt (2016). We think our reasoning is applicable to all variants of the argument, but we will focus on Huemer's formulation, because we think it is one of the argument's more prominent and compelling statements. Meanwhile, Nicholas Dixon (2011) and Jeff McMahan (2012) claim that the argument fails. They say that gun control makes each person safer, and so promotes each person's ability to remain safe from harm. Accordingly, no one's right to physical security is infringed. Huemer (2016) shows that this response doesn't work. Gun control may make people safer on average, but it does not make each person safer, and those who are made less safe are those who Huemer claims have their rights violated.

In this paper, we draw on recent work by Caspar Hare (2016) to show that,

1. This is not the only kind of gun control. For instance, requiring gun owners to register their weapons with a government database, or requiring that guns be stored in a locked cabinet for safety reasons when not in use, would typically be considered gun control measures. But these are not particularly aimed at making it harder for people to obtain guns. 
while Huemer's response to Dixon and McMahan is correct, the argument from the right to self-defense nonetheless probably fails. What matters is whether each person's expected security, given the knowledge available to the government, is increased by a gun control policy. Outside special circumstances (for which whatever provisions are feasible should be made), this means that a gun control policy need only make people safer on average in order to be justifiable from the perspective of protecting the right to security. Of course, there are other arguments against gun control-for instance, from the claim that it would actually backfire and increase crime, or from the autonomy of gun owners (Huemer 2003: §3; Hsiao 2015), or from the recreational value of guns (Huemer 2003: §4.1), or from the supposed role of public gun ownership in preventing tyranny (Wheeler 1999). But Huemer considers the self-defense argument the "main argument on the gun rights side" (2003: 306), and it is the one we will focus on.

In the next section, we survey Huemer's argument, McMahan and Dixon's objection, and Huemer's response. In Section 3, we survey Caspar Hare's argument that there are not conflicts between rational beneficence and morality. In Section 4, we apply this argument to the case of gun control, and state and respond to two objections.

\section{Huemer's Argument}

Huemer focuses primarily on an extreme form of gun control-banning all privately owned guns. This is generally not what proponents of gun control in the United States have in mind, but Huemer thinks that "examining this proposal will enable us to develop the theoretical framework needed for evaluating less extreme forms of gun control" (2003: 304, fn. 14). Huemer goes on to claim that his argument also applies to proposals to ban handguns and concealed weapons, though in a somewhat attenuated form (because these proposals do not infringe the right to self-defense as significantly as would a total ban) (2003: §7). We will follow Huemer in taking a total ban as a starting place, with the caveat that similar reasoning might be applied to less restrictive gun control measures.

Huemer suggests that the bulk of the strength of the right to bear arms is derived from the right to self-defense. The right to bear arms is a so-called "means right," significant largely because owning a gun is, in many circumstances, the most effective means of exercising the more fundamental right to self-defense (\$§2.2 and 4.2). The right to self-defense itself is in turn "a derivative right, serving to protect the right to life among other rights" (2003: 307), such as the right against non-lethal assault. We will refer to this cluster of more fundamental rights under the label "the right to physical security." This right to security is extremely weighty. Since the seriousness of the infringement of a derivative right 
is "proportional to the importance of the other right that it subserves" (2003: 301), and since the right to security is extremely important, infringements of the right to self-defense are extremely serious. So, in turn, are infringements of the right to own a gun, at least where such infringements constitute infringements of the right to self-defense.

Huemer illustrates this point with a series of examples. Holding someone down while someone else stabs them to death, thereby preventing them from defending themselves, is about as bad as directly murdering them, and is clearly much worse than just briefly holding someone down, taken on its own. Suppose now that instead of holding someone down, you grab their gun just as they attempt to defend themselves from a murderer, resulting in their being stabbed to death. That is clearly also very bad. But Huemer claims this is equivalent to what the government does in banning guns. The government will confiscate some weapons which people might have successfully used to defend themselves, resulting in those people falling prey to violent crime (2003: 306-308). ${ }^{2}$

Of course, the government does not know who will be prevented by a gun ban from successfully using firearms in self-defense. (Otherwise, all else equal, it could just let those people keep their weapons.) But Huemer claims that this is irrelevant. He asks us to consider the following case:

An "accomplice" ties up a family of five somewhere in the wilderness where he knows that wolves roam. He has good reason to believe that a pack of wolves will happen by and eat one or two of the family members (after which they will be satiated), but he doesn't know which ones will be eaten. He leaves them for an hour, during which time the mother of the family is eaten by the wolves. (2003: 308-309)

Huemer correctly notes that "the fact that the accomplice did not know who would die as a result of his action does not mitigate his guilt," and goes on to say that "likewise, it is unclear how the state's inability to predict who will become the victims of its anti-gun policy would mitigate the state's responsibility for their deaths or injury" (2003: 309).

The commonsense view is that a right cannot be infringed in order to prevent a small number of comparable rights infringements. For instance, to take a stan-

2. The government does not intend that the people are victimized. So in order for the analogy to go through, Huemer would have to either appeal to a case where you do not intend that the person whose gun you take be harmed, or else deny the moral significance of the distinction between intention and mere foresight. We think either of these routes is successful. If we stipulate that you are taking the gun, not because you want the person to be harmed, but for some other reason, that still seems prima facie seriously wrong. But even if that response doesn't work, we are generally skeptical of the significance of the intention/foresight distinction, so we will not object to Huemer on these grounds. 
dard example, most people would say that a judge cannot order the execution of an innocent person in order to prevent a riot which would kill two or three other innocent people. If there is a point at which the judge could order the execution, it would only be when very many lives are at stake. The same goes for holding someone down as they are stabbed. And, Huemer thinks, the same likewise goes for confiscating guns. It is not enough to show that this would have good consequences; the consequences would need to be many times greater than the harms involved in the many severe rights infringements which confiscating the guns would require (2003: 317-318).

Nicholas Dixon (2011) and Jeff McMahan (2012) have given similar responses to this argument. McMahan writes that

Imposing a ban on guns, [gun advocates] argue, would be tantamount to taking a person's gun from her just as someone is about to kill her. But this is a defective analogy. Although a prohibition would deprive people of one effective means of self-defense, it would also ensure that there would be far fewer occasions on which a gun would be useful or even necessary for self-defense. . . Guns are only one means of self-defense, and self-defense is only one means of achieving security against attack. It is the right of security against attack that is fundamental. A policy that unavoidably deprives a person of one means of self-defense but on balance substantially reduces her vulnerability to attack is therefore respectful of the more fundamental right from which the right of self-defense is derived.

Dixon makes the same argument when he claims that a "[handgun] prohibition neither violates the right to self-defense nor sacrifices anyone's interests for the common good, since it makes each person less likely to be murdered than the current permissive handgun laws" (2011: 151).

Huemer (2016) does not challenge McMahan's claim that the weight of the right to self-defense is derived from the more general right to security; in fact, as we saw earlier, he endorses it. And we agree that at least most of the weight of the right is so derived. If someone acts in a manner that leaves you unable to defend yourself, but also removes any threats against which you might need to defend yourself, they have not thereby seriously infringed your right to selfdefense. Presumably, what is of fundamental importance is remaining safe, and defending yourself is only one means to that. If anything, since using a gun in self-defense is often harrowing and traumatic, preventative measures seem superior to self-defensive ones, all else equal. ${ }^{3}$

3. Admittedly, not everyone will agree with this. However, our position may be able to accommodate certain other positions more easily than might initially seem to be the case. For in- 
Instead, Huemer points out that many particular individuals may be made less safe by a gun ban. ${ }^{4}$ If someone faces a serious threat from violent crime, the threat may not go away if a gun ban is implemented, and a gun is a much better means of defense against that threat than anything else available, that person may be greatly endangered if guns are outlawed. As examples, Huemer asks us to consider a woman with an abusive, estranged husband, much stronger than her, whom she could only successfully repel with a gun, and a man who must walk home from work through gang territory. In these scenarios, if no one has a gun, the aggressor will win. Huemer then asks us to

suppose the woman with the violent husband turns up at a gun store. And suppose they send her away, because a new law has just been passed that says only government agents are allowed to buy guns. How is she made safer by this? I am not asking how society might be made safer. I am asking about that individual, who went to buy a gun to protect herself - she was not worried about gun violence in society, she was worried about her abusive husband. So how is she more secure?

She is not. And, as Huemer notes, these are "hardly outlandish scenarios." Thus, it looks as if the physical safety of many particular individuals is undermined by a gun ban. So the Dixon/McMahan argument fails. Gun control may make people safer on average, but it does not make each person safer, and those individuals who are made less safe are those who Huemer claims have their rights violated. But while the Dixon/McMahan argument fails, perhaps something in the neighborhood works.

stance, Dan Demetriou (2016) acknowledges that "philosophers on both sides of the gun control debate typically assume that a moral right to guns is contingent on whether guns really do make us safer." But Demetriou himself claims that violent resistance to attack is often more dignified than other means of resistance to attack, and that this gives some reason to prefer violent resistance (along with the means to effective violent resistance, including guns) to other forms of resistance, even if violent resistance will be somewhat less effective. But the point of a gun control policy is often to reduce the chance that you come under attack at all, and thus the chance that you need to offer any form of resistance; even if violent resistance is more dignified than other forms of resistance, it's not clear that it's more dignified than avoiding assault altogether. In any event, our own sense is that, even if there are some reasons to care about self-defense besides just our reasons to care about physical safety, and even if these are sufficient to outweigh the trauma based reason mentioned in the main text for preferring preventative measures, the remaining strength of these reasons will not be sufficient to justify sacrificing very much in the way of safety. Respecting the right to self-defense will then be primarily a matter of respecting the underlying right to physical security. The upshot for our argument would be that, even if the government cannot justifiably implement gun control when it would do only slightly more good than harm, it would be enough for it to do just somewhat more good, rather than, as Huemer claims, many times as much good.

4. A similar point is made by Deane Peter-Baker (2014). 


\section{Wishing Well to All}

Caspar Hare has recently given an argument against moral theories which claim that "sometimes it is wrong for you to act as you would if you were reasonable and moved solely by individual concern for each one of the people affected by your actions" and which thereby "generate conflicts between reasonable beneficence and morality" (2016: 451). The application of interest to us involves the famous Footbridge case, in which we must decide whether to push someone in front of a trolley in order to stop it and save five people. Primarily, we are interested in a variant Hare calls Footbridge with Suitcases, where, though we can push one to save five, we do not know who is on the footbridge and who is on the trolley track. This is because everyone is locked in suitcases, and we don't know who is in which suitcase. If we push, the person on the footbridge will die, and the people on the tracks will be saved. Given the information available, pushing gives each person a $1 / 6$ chance of death, and a $5 / 6$ chance of survival. The opposite is true of not pushing. If we want to maximize each person's chance of survival given our evidence, we should push. Any theory which claims we shouldn't push therefore generates a conflict between morality and reasonable beneficence (2016: 454-455).

It may seem intuitively obvious that this is a problem. Hare also gives three arguments for the conclusion that it is. We will only briefly mention two of them, before focusing on the third. The first is from presumed consent: presumably, everybody involved would, quite reasonably, consent to your pushing the suitcase, if given the opportunity. This might be thought to justify pushing (2016: 457). The second, from dirty hands, relies on Hare's earlier work (2013: ch. 3) on which preferences are demanded by "minimal decency." It asserts that "if you willingly refrain from pushing and you are rational then you must prefer outcomes in which everybody, including you, is worse off over outcomes in which everybody, including you, is better off. But it is indecent to have preferences like that" (2016: 457). But the third argument, from composition, is the one which Hare stresses. The central idea is that in cases like Footbridge with Suitcases, pushing is morally equivalent to a series of actions, each of which you ought to perform, and that therefore you ought to push.

Suppose there are six suitcases, five on the tracks and one on the footbridge. By pushing the suitcase from the footbridge onto the trolley tracks, we can stop a runaway trolley from hitting the other five. Only one person is in one of the suitcases, and, sadly, we don't know which suitcase it is. If we push, there is a $1 / 6$ chance that we kill the person (who otherwise would have been fine), and a $5 / 6$ chance that we save the person (who otherwise would have died). Both rea- 
sonable beneficence and morality suggest that we subjectively ought ${ }^{5}$ to push. Of course, there is some chance that we will accidentally kill them, but this is also true of, say, surgeons who perform medical procedures (2016: 459). What matters is that pushing maximizes their chance of survival. Note that nothing seems importantly different if the probabilities are closer than $5 / 6$ and $1 / 6$; in fact, we think it is plausible that you should push even if there is only, say, a fifty-one percent chance that this saves them, and a forty-nine percent chance that it kills them. There doesn't seem to be an argument of any appreciable strength from the person's right to life or to physical security against pushing in such a situation, since, given your knowledge, pushing maximizes their chance of being saved. (If that doesn't seem obvious, Hare, 2016: 460, asks you to imagine what you would do if it was your loved one in one of the suitcases. Wouldn't you prioritize their chances of survival over things like avoiding being the cause of their death?)

Now consider Six Tracks (2016: 458). Suppose there are six tracks just like the one described above. For each track, one person is either in a suitcase on the track or a suitcase on the footbridge above the track. Five people are on the tracks, and one is on the footbridge. No one knows who is on the footbridge, or which track they are above. For each track, you must decide whether to push. This is an iterated version of the case in the previous paragraph. Just as you ought to push when there is only one track, it seems that, for each track, you ought to push. By Weak Agglomeration:

For any composite action $A_{1} \ldots A_{n}$, if irrespective of whether you do $A_{2}$ through $A_{n}$ you ought to do $A_{1}$, and ... and irrespective of whether you do $A_{1} \ldots A_{n-1}$, you ought to do $A_{n}$, then you ought to do $A_{1} \ldots A_{n}$. (2016: 460)

you therefore ought to push every suitcase on the footbridge, thereby killing one and saving five. Weak Agglomeration is necessary to rule out moral dilemmas, and is therefore very plausible. ${ }^{6}$

It might be claimed that whether you should push any given suitcase is not independent of whether you push the other ones. Maybe you should push one, but shouldn't push so many that it becomes too likely that you kill somebody at some point or other. But this is implausible. Similar reasoning would apparently suggest that doctors who perform dangerous surgeries should retire before the likelihood that they cause the death of a patient at some point in their

5. What we subjectively ought to do is what we ought to do relative to the information we have; see Hare (2016: 458-459).

6. For two classic, and extremely compelling, arguments against moral dilemmas, see McConnell (2014: §4). 
careers becomes too high. But no one thinks that (2016: 459). Also note that what seems to matter is the information available to the agent, whatever information is available to the patient. If the people in the suitcases know whether they are on the tracks or the footbridge but we do not, this doesn't make any difference to whether we (subjectively) ought to push. As Hare (in the course of discussing a variant case which involves pressing buttons that move the suitcases, rather than pushing the suitcases directly) puts the point,

I say that, although you cannot anymore take solace in the thought that each one of them wants you to press, the argument from composition still applies. Ought you press, e.g., the 'Move Alexia' button? There's a $5 / 6$ chance that Alexia is thinking "Please, please, press that button - it will save my life and affect nobody else." There's a $1 / 6$ chance that she is thinking "Please, please, don't press that button - it will kill me and affect nobody else." Pressing remains the thing to do. (2016: 466)

In this version of the case you can no longer be confident that each person would consent to your pushing (if they were offered the choice while possessing their evidence, rather than yours). But we agree with Hare that this does not seem to change what you ought to do. Suppose a doctor knows that there is a high chance that their patient will be saved if a certain medicine is administered, and a small chance that the medicine will cause a lethal allergic reaction where the patient might otherwise have lived. Suppose the doctor knows that the patient (who is unconscious, or unable to communicate for some other reason) knows whether they are allergic. Unless this latter piece of information itself provides some evidence as to whether the patient really is allergic, it does not seem to change the fact that the doctor ought to administer the medicine.

If there is an important difference between Six Tracks and Footbridge with Suitcases, it presumably has to do with the fact that the death of the one is a means to saving the five in the latter but not the former. To address this, Hare (2016: 461-463) gives a more convoluted variant of Six Tracks which seems morally analogous and in which the killing of the one causes the saving of the five. We agree that the variant is analogous, but it doesn't really matter for our purposes. Outside odd cases, taking guns from law-abiding citizens who might use them in self-defense is not a means to whatever benefits are achieved through gun control. (If we knew that these people would wind up using their guns in self-defense, and wouldn't do anything bad with them, we would just let them keep their guns.) All we need is the claim that you should push all the suitcases in Six Tracks.

We find it plausible that you ought to push in Six Tracks and Footbridge with Suitcases even if you should not push in the original Footbridge case (where you 
know the identity of the person on the bridge). This reveals that uncertainty about who will be harmed by an act may affect the permissibility of an act. Specifically, it is commonly thought that one has more reason to avoid killing than to avoid allowing a killing, or to avoid infringing a right than to avoid allowing a right to be infringed, or to avoid causing harm than to avoid allowing harm to occur. But cases like Six Tracks and Footbridge with Suitcases seem to show that these considerations do not have much (if any) force when making choices in particular circumstances of uncertainty-namely, those where killing (or whatever other action is in question) promotes the safety, given your evidence, of everyone, including the person killed.

Though we agree with thrust of Hare's argument, we will qualify it in one important way. Hare ultimately frames his argument in welfarist terms: there is no conflict between morality and beneficence, what is expectedly best for everyone. But we are open to the view that we can have reasons to care about things besides our own welfare, which are nonetheless the right type of reasons to ground obligations to us. These reasons are, in Scanlon's (1998: 219) terminology, "personal reasons," reasons which "have to do with the claims and status of individuals in certain positions" even if not with those individuals' well-being. For instance, perhaps we have reasons to care about being treated fairly (1998: 212-213), or being allowed to pursue our own projects (Huemer 2003: 300-301), apart from the effect of these things have on our welfare. So perhaps there is no conflict between morality and concern for the things each individual has personal reason to care about, but there may nonetheless be one between morality and beneficence, if personal reasons outstrip welfarist ones. In light of this, instead of Hare's general claim about beneficence, the specific lesson we wish to draw from Six Tracks is this: the individual right to physical security is generally ${ }^{7}$ not violated by performing an action which maximizes each person's expected safety. ${ }^{8}$ (As we discuss in Section 4.1, this is a specific version of a more general principle which we also endorse, and which can be defended by a somewhat similar case we call Gun Switching). To the extent that the weight of the right to self-defense is derived from the weight of the right to physical security, performing the action in question will not violate the right to self-defense any more than it violates the right to physical security. And we suggested above, and Huemer seemed to agree, that at least the vast bulk of that weight is so derived.

7. One possible exception is when an individual waives their right to protection against some risks and not others; we discuss this possibility in Section 4.2.

8. A referee invites us to consider a view on which the right to own a gun is grounded in the right to life, rather than the broader set of rights included under the banner 'physical security'. We think that Six Tracks also reveals that the individual right to life is not violated by performing an action which maximizes each person's expected safety. So the defense of gun control we ultimately give based on the lesson of Six Tracks would go through even on this 'right to life' based defense of gun ownership. 


\section{Application to Gun Control}

Suppose a comprehensive gun ban will prevent more violent crime than it causes, thereby making most people safer, but that people in circumstances like those Huemer describes will be made less safe. Under these conditions, what is the best way to respect the right to physical security? Suppose the government can reliably recognize those competent, law-abiding citizens who need guns for security reasons like those Huemer describes. Even staunch gun control advocates might agree, whether for consequentialist or rights-based reasons, that exceptions should be made for these people. So, for instance, David DeGrazia argues that handguns should be restricted to people who demonstrate a special self-defense related reason for owning guns which means that they "cannot prudently delegate their right to fight off intruders to the police" (2016: 72) and who "pass a demanding, in-depth, federally approved course in handgun safety" (2016: 74). DeGrazia cites (2016: 74) as people who might have a special need for a gun those who live in unsafe neighborhoods or live in isolated areas with a slow police response time. Presumably, Huemer's person with the violent, estranged spouse would also qualify. DeGrazia's preferred policy would constitute a "restrictive licensing" system similar to that found in Canada, where people can own handguns only upon demonstrating a special self-defense related need for them, or meeting one of several other conditions (see Vernick, Hodge, \& Webster 2007 for a positive evaluation of this system). If the government could identify such people with perfect accuracy, then Huemer's argument against a total gun ban might succeed, but would be ineffective against this other, still very restrictive, gun control policy.

But suppose that, for whatever reason, many people who have such a special need will be unable or unwilling to demonstrate this to the government. (Someone's testimony that they need a gun, all on its own, would likely provide little evidence that they have such a special need, since many people would falsely claim that they have one, either due to being mistaken about the danger they face or due to being willing to lie to get a gun. So more than mere testimony would be needed, if the licensing system is to serve any purpose.) People with such a special need may be put at greater risk under a restrictive licensing system than they would be under a more permissive gun policy, even if the average person is made safer. In that case, we claim that the government is in a position similar to that of the agent in Six Tracks, and those who are denied guns are similar to those in the suitcases. The government will harm some of those people if the policy is implemented, but it does not know whom, and given the information available to it, each affected person's chance of remaining safe is increased by the policy. Insofar as we aim to maximize each person's chance of remaining safe, then, we should implement the gun control policy (or some other policy 
that makes everyone even safer, if there is one). And therefore, ceteris paribus, we should implement it (or some other, better policy,) just as we should push each suitcase in Six Tracks. There is no requirement that "many, many times" as much good be done as harm. (We discuss two important potential disanalogies with Six Tracks below).

We can see, then, why gun control may be like Six Tracks: uncertainty about who will be harmed may mean that each person's chance of survival is maximized by taking the paradigmatically consequentialist course of action. This is not true in Huemer's wolf case, where respect for each individual's safety demands that no one be left out for the wolves. Accordingly, the fact that uncertainty makes no difference in the wolf case doesn't mean it makes no difference to Six Tracks-or, for that matter, to gun control.

\subsection{First Objection}

Here is an objection: Six Tracks decomposes into a series of pushes, each of which maximizes the chance of survival of the person involved without affecting anyone else. A restrictive licensing system decomposes into a series of what we might call "gun denials" - either preventing someone from buying a gun or (in the most extreme versions of such a system) confiscating a gun they already own. But for the most part, people aren't at risk of violence due to their having a gun, but due, if anything, to the fact that other people have guns. So each gun denial makes the person being denied less safe, by depriving them of a means of self-defense, in order to make others safer. What would actually maximize the safety of any given person to whom we deny guns is denying guns to everyone else, while allowing them to have whatever guns they wanted. So no actual act of gun denial is beneficent towards the person most affected by it-namely, the person denied a gun - and, in fact, there is no course of action which maximizes every person's safety. This may be an important disanalogy between gun control and cases like Six Tracks: it seems to show that the special kind of uncertainty present in the cases Hare describes isn't present in the gun control case after all.

There are roughly two ways to respond to this. One admits the disanalogy with Six Tracks. However, it claims that, while the gun control policy does require performing individual actions which make particular individuals less safe, it nonetheless does not violate the right to security because these actions are parts of broader courses of action which maximize each individual's chance of safety among those courses of action which aren't otherwise impermissible. The other denies the disanalogy altogether, instead arguing that even the individual act of gun denial does maximize the safety of the person being denied a gun. We will consider two ways of defending this latter claim. We take each type of response in turn. 
Here is the first type of response. It grants the disanalogy with the cases Hare discusses, but argues that it is not ultimately important, so that the pro-gun control argument still goes through. Six Tracks seems to show that the right to security is not violated by taking an action which maximizes everyone's chance of survival, even if this will in fact kill some people. The claim here would be that the right to security is not violated by taking a course of action which, out of those courses which are not otherwise impermissible, maximizes everyone's safety. Six Tracks also meets this description, but on this view, it is a kind of special instance falling under a more general principle: being composed of actions which maximize everyone's safety is one way to fulfill this criterion, but not the only one. Consider:

Gun Switching: Abby and Bob are each under unjust assault. Trolley A contains a shotgun which it is about to deliver to Abby, and Trolley B contains a sniper rifle which it is about to deliver to Bob. The sniper rifle is better against distant opponents, while the shotgun is better against nearby opponents. Abby's opponents are mostly distant; with just the shotgun (which is what she'll get if we do nothing), she has a $25 \%$ chance of survival, while, with just the rifle, she has a $75 \%$ chance of survival. Bob's situation is reversed: with just the rifle (which he'll get if we do nothing), he has a $25 \%$ chance of survival, while with just the shotgun, he has a $75 \%$ chance of survival. If either person had both guns, they would have a $90 \%$ chance of survival, and the other person would only have a $5 \%$ chance. We can move the shotgun to Trolley B instead, so Bob gets it, and can move the sniper rifle to Trolley A, so Abby gets it. We can do both of these actions (giving each person a $75 \%$ chance of survival), neither (leaving each person with a $25 \%$ chance of survival), or just one (so one person gets both guns, giving them a $90 \%$ chance but the other only a $5 \%$ chance). There is some chance that doing both will result in the death of someone who would have survived had we done neither (e.g., though Abby having the rifle rather than the shotgun makes her safer relative to our evidence, it might be that lacking the shotgun will result in her death where she otherwise would have survived).

Here, it seems clear to us that we ought to switch both guns, giving Abby the rifle and Bob the shotgun, and thereby increasing the odds of survival for each to $75 \%$. It also seems clear that if the case is iterated, we ought to keep switching, even if this is statistically certain to eventually cause the deaths of some people who would have survived had we done nothing. This is true even though switching requires performing an individual action which makes each person less safe (Abby is made less safe by moving the shotgun to Trolley B, while Bob 
is made less safe by the other action). So it seems that what matters is whether a whole course of action maximizes each person's safety, not whether each individual action does.

Suppose Abby still complains that our switching the guns violates her right to self-defense. After all, while our course of action made her safer than if we'd done nothing, it didn't maximize her safety, since there was another course of action - giving her both guns - which would have made her safer still. The problem with Abby's complaint is that this alternative course of action seems impermissible on other grounds: for instance, it seems clearly unfair to Bob to give Abby his gun but not the reverse. In determining whether a course of action demonstrates adequate concern for each person's security by maximizing their chance of survival, it makes sense to exclude courses which are impermissible on other grounds. By way of analogy, suppose you could save all six people in Six Tracks without pushing, but only by killing one hundred others. Pushing is still the act that demonstrates adequate concern towards each of the six when we restrict your options to those that are not otherwise impermissible. Thus, pushing is still permissible.

We can see the application to gun control. Suppose you'd be safest if the government took guns from everyone except you. It's not even clear that the government could do this; it might be politically infeasible. But suppose it could. It seems independently wrong for the government to arbitrarily privilege you in this way, denying guns to others to make you safer, while refusing to do the reverse. Of course, there may be other courses of action which would also make you safer than the gun control policy (i.e., denying guns to everyone except you and one other person, etc.) But these face the same problem. So, though taking your gun does make you less safe, and though there are other courses of action which would make you safer, taking your gun is part of the course of action which makes you safest without being otherwise impermissible. So, we claim, it doesn't violate your right to security, or your derived right to self-defense.

An alternate response involves denying the disanalogy with Six Tracks altogether and arguing that denying you a gun does make you safer, relative to the government's evidence. We will consider two ways of defending this. The first appeals to the risk of suicide. In the United States, there are far more firearm suicides than homicides of any sort (CDC 2016a; 2016b). And there are reasons to think that many of those who die from suicide would not, if not for the availability of firearms. Suicide rates are higher in areas with high rates of gun ownership, and the correlation remains even after potential confounders are controlled for through statistical regression; by one estimate (Briggs \& Tabarrok 2014), the suicide rate increases by between .5 and $.9 \%$ for each percentage point increase in household gun ownership rates. And there is a compelling explanation of this. First, suicide by gun is easy to carry out, assuming a gun is available-all 
one must do is pull a trigger. And suicide is often an extremely impulsive act (in one study, Deisenhammer et al. 2009, nearly half of people who survived a suicide attempt reported spending less than ten minutes considering the attempt immediately before making it). Accordingly, the more time and effort someone must go to in order to attempt suicide, the more likely they are to change their mind. Second, firearms are several times as lethal as other commonly used suicide methods (Shenassa, Catlin, \& Buka 2003). Research suggests that the vast majority of people who attempt suicide once and survive do not ultimately die by suicide, with most never even attempting suicide again (e.g., O'Donnell, Arthur, \& Farmer 1994; Owens, Horrocks, \& House 2002; Suominen et al. 2004). Accordingly, the lethality of one's attempted suicide method is a major determinant of whether one ultimately dies by suicide. Though complicated empirical questions are involved, it would not be surprising if the reduced risk of death by suicide due to a gun denial outweighed any increased risk of crime victimization for very many people, relative to the information available to the government.

On the matter of suicide, Huemer writes that

it is doubtful that the restriction of gun ownership for the purpose of preventing suicides would fall within the prerogatives of a liberal state, even if such a policy would be effective. One cause for doubt is that such policies infringe upon the rights of gun-owners (both the suicidal ones and the non-suicidal majority) without protecting anyone else's rights. Another cause for doubt, from a utilitarian perspective, is that one cannot assume that individuals who decide to kill themselves have overall happy or pleasant lives; therefore, one should not assume that the prevention of suicide, through means other than improving would-be victims' level of happiness, increases utility, rather than decreasing it. (2003: 311)

Regarding the rights claim, Huemer cites Todd Hughes and Lester Hunt, who write that restricting guns in order to prevent suicide is "clearly paternalistic. Suicide belongs, if anything does, to the private domain that is protected even by the minimal interpretation of the autonomy constraint [which liberal governments should obey]" (2000: 13). But it is plausible that many suicides are not autonomous, considered choices which must be respected, but are instead the result of mental illness or of being overwhelmed by circumstances. (Outside of special circumstances, very few of us think that interfering with a suicide attempt is usually prima facie seriously wrong in the way that interfering with important, autonomous choices which someone makes about their own life generally is.) If suicide is better thought of as a mental health issue than an autonomous choice, then it becomes less clear that those who may attempt suicide do not have a positive right (similar to the right to healthcare which some people believe we have) 
to have steps taken to reduce their risk of death. As for the utilitarian argument, suicide is often a response to temporary problems which can ultimately be overcome; recall that the vast majority of those who survive a first suicide attempt do not ultimately die by suicide. It seems plausible that most cases of suicide are not what is best for the person involved. (Presumably, this is another part of why we think it's usually fine to interfere with suicide attempts.) So we reject this argument.

A separate way of arguing that gun denials increase the safety of those denied guns involves Hare's (2016: §6) account of what it takes to know which people will be harmed by an action. Suppose that in Six Tracks, you say "Let 'Bridgey' refer to the person I will kill if I push all the suitcases." It is plausible that you successfully baptize that person with the name "Bridgey." You then know that Bridgey is the person who will be killed if you push all the suitcases. However, it does not seem plausible that knowing this stupid fact could make any difference to whether you ought to push. So either it doesn't matter at all whether you know who will be harmed, or else "knowing who will be harmed," in the relevant sense, requires something more than simply knowing a proper name for the person who will be harmed.

Hare (2016: §6) prefers the second option. Knowing who your victim will be, in the relevant sense, involves knowing some of the various details which make them importantly different from other people. These involve things like the fact that they do funny impressions, that they have a son or an unfinished sonata (2016: 467), that they are good at writing balladic poetry and that their mom called them "Bugaboo" (2016: 469), and so on. These are important because once one has enough information like this, one has incommensurable reasons for action (e.g., that pushing all the suitcases will save the most lives and will allow someone to keep doing funny impressions for their friends, while refraining will return a father to his son and allow someone to finish their sonata). Once one's reasons are incommensurable, it is no longer the case that one should push, though Hare thinks one is still permitted to. 9

However, the government does not know anything about most individuals, apart from some very general demographic facts. For instance, a certain agency may have on record that there is someone named Bob Smith, that he lives in Millersburg, Missouri, that he is forty-eight years old and made fifty-one thousand dollars last year, and so on. These facts may provide the government with special reasons for action in certain cases-for instance, when administering some

9. Of course, even before one knows these personal details, one knows that there are personal details which are such that, if known, they would provide one with incommensurable reasons for action. But Hare thinks that knowing this doesn't provide one with incommensurable reasons for action, since it is impossible to act on these reasons without knowing their content; see Hare (2016: $470-471$ ). 
program which is justifiably aimed at benefiting members of a certain demographic group. But at least under normal circumstances, it is not clear that this sort of information will provide any reason to exempt Bob Smith from a gun ban.

Perhaps the government even knows facts such as "Bob Smith is a parent." This fact might seem to be a better candidate for providing incommensurable reasons for action. However, since other parents may be endangered by exempting Bob from a gun policy, it is plausible that the reason his being a father provides for exempting him is countered by commensurable reasons pushing in the other direction. Perhaps incommensurable reasons would only arise if the specific details which make Bob's relationship with his children unique were known. But the government doesn't know those details, so the government may not have the right kind of information regarding Bob needed to generate incommensurable reasons.

On Hare's view, the government may not have the right kind of information for trading off risks between Bob and others to provide it with incommensurable reasons. It may then be that, in the relevant sense-the sense in which I don't know who Bridgey is - the government does not know to whom it is denying a gun when it denies a gun to Bob Smith, since it does not know who Bob Smith is. Each individual act of gun denial might then maximize each person's safety, even if it made the person being denied a gun less safe, because, in the relevant sense, the government would not know who was being denied a gun.

Of course, certain agents within the government will have special information about people they know: a member of the Bureau of Alcohol, Tobacco, Firearms, and Explosives may know something totally unique about their child. Most of the time, these agents won't be in a position to ensure the passage of a gun ban that makes an exception of the people they know. But even if they are, it is plausible that considerations about avoiding cronyism mean they shouldn't act on this information in official contexts. For instance, most of us think it would be wrong for a president to use their power to provide special benefits to people they know, even if they have reason to privilege these people when acting as a private citizen. So this does not undermine this line of response.

\subsection{Second Objection}

Here is a second objection: one of Hare's arguments was from "presumed consent." But we know that many gun owners would not, in fact, consent. This undermines that argument. Further, perhaps it calls into question whether we can apply Six Tracks type reasoning to the gun control case. For instance, one could attempt to argue that gun owners who refuse to consent to the gun control policy are willing to waive their rights against the risks associated with a libertarian gun policy, but not against the risks associated with gun control. Perhaps 
it would then be illegitimate to argue that can respect their rights by appealing to the former risks to justify imposing the latter risks.

In responding to this objection, we should distinguish between two groups within the population of people who would not consent to a gun control policy, and would be denied guns (or guns of some certain sort) under it: those who would be made safer by the policy, and those who would be put at greater danger. Consider the former group first. These people may have other reasons for opposing gun control besides wanting guns for self-defense-for instance, they may want certain guns for recreational purposes. Since we are concerned only with the extent to which the right to physical security supports the right to bear arms, we will set these other reasons aside in this paper. To the extent that people refuse to consent to gun control for reasons of personal safety even though it would make them safer, they would seem to be misinformed or irrational. What is the normative status of their refusal to consent in light of this?

One view would be that what fundamentally matters in such a situation is what one's rational, fully informed self would want done in the relevant circumstances, where the "relevant circumstances" are taken to include one's actual lack of consent (see Parfit 2011: 191-200 for discussion of this view). Unless being denied a gun against one's will is an extremely heavy cost, it seems that if a gun control policy maximizes one's safety, and if one's reason for wanting a gun is personal safety, then one's rational, fully informed counterpart would, so far as one's own interests were concerned, want the gun control policy implemented, even over one's actual objections to it. In this case, an argument from presumed consent would fail, but an analogous argument from hypothetical consent would succeed.

But suppose this isn't right, and what fundamentally matters is just actual consent or refusal. Setting aside worries about mental competence like those discussed in connection to suicide in the last section, if denying you a gun was primarily meant to keep you safe, perhaps your refusal to consent would be a very strong reason not to deny you a gun. Perhaps, for instance, you shouldn't push a suitcase onto the track in Six Tracks if you know that the person on that track, for some strange reason, irrationally wants you not to. But remember, from the last subsection, that if gun control makes person safer from crime, it makes each person safer primarily by denying guns to others, and the government probably must apply gun regulations to everyone equally without making arbitrary exceptions for any one person. The question is then whether some people, by misguidedly refusing to consent to a gun control policy, can veto it, thereby imposing a greater risk on others. And the most plausible answer is that they can't. Consider a variant of Six Tracks in which we must push all the suitcases or none of them (perhaps, to consider a version found in Hare, 2016: 463, we must either push a button which will cause all six suitcases to be pushed, or do nothing). 
Suppose we knew that some of the people in the suitcases would irrationally refuse to consent to our pushing the button, despite the fact that it both saved the most lives and maximized their own chance of survival. In that case, it seems that we ought to push, even over their objection. We should not let their irrationality or ignorance endanger others.

The harder cases deal with those competent, law-abiding citizens who refuse to consent and who know that they will be made substantially less safe by the policy. When a course of action is impersonally best but will make one much worse off, it's plausible that one could often either rationally consent to it or rationally refuse to consent (see Parfit 2011: 131-149 and 182-189). Accordingly, we cannot dismiss these people as irrational or ill-informed, as with the previous group. Hopefully, there will not be many such people. But even those there are do not pose a threat to our argument.

We claim that these cases are analogous to versions of Six Tracks where the people know which suitcase they are in but cannot share this information with us. The government knows that some people will reasonably refuse to consent to a policy that denies them guns, since it will render them less safe, even though it renders most people more safe. To the extent that the government can identify these people, we have suggested that they ought to be allowed guns, absent overriding reason to the contrary. But there are (we're supposing) some such people who the government cannot identify. They would like to have guns but cannot differentiate themselves from people who don't have a special defenserelated need for them. In this case, assuming that people who can't demonstrate such a special need are, on average, made safer by the policy, a concern for protecting each individual's safety would seem to support implementing the policy. After all, to echo Hare, there is some chance that each person is thinking "Please, please, don't deny me a gun," but a greater chance that they are (or should be) thinking "Please, please, implement that policy." They may know they will be made less safe, but if the government does not have good evidence for this - and we're supposing it doesn't - this doesn't change what the government subjectively ought to do, anymore than in the case involving a doctor who knows their patient knows whether they are allergic, but still doesn't know whether they are. $^{10}$

10. A referee asks whether all greater good promoting policies can be justified by our style of argument. Is there something special that separates the gun control issue from at least some other greater good promoting policies, or does the argument generalize without exception? If the argument does generalize without exception, our account might seem to have implausible implications. For instance, someone might think that, if parallel reasoning also licenses the government subjecting one hundred people to involuntary and inevitably lethal medical experiments in order to prevent one hundred and one deaths from disease, this would be a reason to reject our argument. We can't fully explore this issue here, but we will note that it isn't obvious that the argument generalizes in this way. For instance, suppose the rich have a right to a certain percentage of their 


\section{Acknowledgements}

Thanks to Ben Bronner, Minji Jang, Jonathan Mahoney, Jesse Spafford, audiences at the Central APA and RoME, and two anonymous referees for helpful comments.

\section{References}

Briggs, Justin and Alexander Tabarrok (2014). Firearms and Suicides in US States. International Review of Law and Economics, 37, 180-188. https://doi.org/10.1016/j. irle.2013.10.004

Center for Disease Control and Prevention (2016a). FastStats: Assault or Homicide. Retrieved from from https://www.cdc.gov/nchs/fastats/homicide.htm

Center for Disease Control and Prevention (2016b). FastStats: Suicide and Self-Inflicted Injury. Retrieved from https://www.cdc.gov/nchs/fastats/suicide.htm

DeGrazia, David (2016). Handguns, Moral Rights, and Physical Security. Journal of Moral Philosophy, 13(1), 56-76. https://doi.org/10.1163/17455243-4681055

Deisenhammer, Eberhard A., Chy-Meng Ing, Robert Strauss, Georg Kemmler, Hartmann Hinterhuber, and Elisabeth M. Weiss (2009). The Duration of the Suicidal Process: How Much Time is Left for Intervention Between Consideration and Accom-

income. And suppose that taxing some of this income (to which they have a right) would promote the greater good by benefiting the poor, but the rich would be left worse off. It seems clear that, if the government knows who the rich are, then the government is not acting in their expected best interests by implementing the tax. So, in order to defend this tax policy via our style of argument, one would have to lean on the claim that the government does not know who the rich are. In contrast, as we saw in Section 4.2, there are at least two other strategies available for proponents of gun control. Further, as we briefly noted in Section 4.2, there may be cases in which certain demographic characteristics do provide the government with special reasons for action. For instance, maybe the government has special reason to avoid implementing policies which disproportionately harm racial minorities. In that case, knowing that racial minorities would be the ones harmed by a greater-good promoting economic policy might itself be enough for the government to know who, in the relevant sense, is being harmed, even if it doesn't know who, in the relevant sense, is being harmed in the gun control case.

Further still, our focus on personal reasons, rather than the narrower category of welfarist reasons, may also sometimes prevent the argument from generalizing. Return to the medical experiment case. It might be plausible to think that one has somewhat stronger reasons to want to avoid being knowingly killed as part of a state-sanctioned experiment than to want to avoid death by disease, even if both deaths would be equally bad from a welfarist perspective. Accordingly, even if this policy would promote the greater good, it may nonetheless be a bad way of respecting the full range of things individuals have reason to care about. (Of course, gun control opponents might themselves claim that there are special reasons to want to avoid harm as the result of a gun control policy, even if it makes one statistically safer. But we already discussed this move in Footnote 3). In light of considerations like these, we suspect that whether other greater-good promoting policies will be vindicated by arguments parallel to ours will be need to be handled on a case-by-case basis. 
plishment of a Suicide Attempt? Journal of Clinical Psychiatry, 70(1), 19-24. https://doi. org/10.4088/JCP.07m03904

Demetriou, Daniel (2016). Our Dignity-Right to Guns. The Critique. Retrieved from https://web.archive.org/web/20170613014839/http://www.thecritique.com/articles/ our-dignity-right-to-guns/

Dixon, Nicholas (2011). Handguns, Philosophers, and the Right to Self-Defense. International Journal of Applied Philosophy, 25(2), 151-170. https://doi.org/10.5840/ ijap201125215

Hall, Timothy (2006). Is There a Right to Bear Arms? Public Affairs Quarterly, 20(4), 293312.

Hare, Caspar (2013). The Limits of Kindness. Oxford University Press. https://doi. org/10.1093/acprof:oso/9780199691999.001.0001

Hare, Caspar (2016). Should We Wish Well to All? Philosophical Review, 125(4), 451-472. https://doi.org/10.1215/00318108-3624764

Hsiao, Timothy (2015). Against Gun Bans and Restrictive Licensing. Essays in Philosophy, 16(2), 180-203. https://doi.org/10.7710/1526-0569.1531

Huemer, Michael (2003). Is There a Right to Own a Gun? Social Theory and Practice 29(2), 297-324. https://doi.org/10.5840/soctheorpract200329215

Huemer, Michael (2016, July 14). Gun Rights \& Noncompliance. The Critique. Retrieved from http://www.thecritique.com/articles/gun-rights-noncompliance/.

Hughes, Todd C. and Lester H. Hunt (2000). The Liberal Basis of the Right to Bear Arms. Public Affairs Quarterly, 14(1), 1-25.

Hunt, Lester H. (2016). The Case Against. In David DeGrazia and Lester H. Hunt (Eds.), Debating Gun Control: How Much Regulation Do We Need? (3-115). Oxford University Press.

McConnell, Terrance (2018). Moral Dilemmas. In Edward N. Zalta (Ed.), The Stanford Encyclopedia of Philosophy (Fall 2018 ed.). Retrieved from https://plato.stanford.edu/ entries/moral-dilemmas/

McMahan, Jeff (2012, December 19). Why Gun 'Control' is not Enough. The New York Times. Retrieved from http://opinionator.blogs.nytimes.com/2012/12/19/why-guncontrol-is-not-enough/

O'Donnell, I., A. J. Arthur, and R. D. Farmer (1994). A Follow-Up Study of Attempted Railway Suicides. Social Science and Medicine, 38(3), 437-442. https://doi.org/10.1016/02779536(94)90444-8

Owens D., J. Horrocks, and A. House (2002). Fatal and Non-Fatal Repetition of SelfHarm. Systematic Review. British Journal of Psychiatry, 181, 193-199. https://doi. org/10.1192/bjp.181.3.193

Parfit, Derek (2011). On What Matters. Oxford University Press. https://doi.org/10.1093/ac prof:osobl/9780199572816.001.0001

Peter-Baker, Deane (2014). Gun Bans, Risk, and Self-Defense. International Journal of Applied Philosophy, 28(2), 235-249. https://doi.org/10.5840/ijap2014111826

Scanlon, T. M. (1998). What We Owe to Each Other. Harvard University Press.

Shenassa, E. D., S. N. Catlin, and S. L. Buka (2003). Lethality of Firearms Relative to Other Suicide Methods: A Population Based Study. Journal of Epidemiology and Community Health, 57(2), 120-124. https://doi.org/10.1136/jech.57.2.120

Suominen, Kirsi, Erkki Isometsä, Jaana Suokas, Jari Haukka, Kalle Achte, Jouko Lön- 
nqvist (2004). Completed Suicide After a Suicide Attempt: A 37-Year Follow Up Study. American Journal of Psychiatry, 161(3), 563-564 . https://doi.org/10.1176/appi. ajp.161.3.562

Vernick, Jon S., James G. Hodge, and Daniel W. Webster (2007). The Ethics of Restrictive Licensing for Handguns: Comparing the United States and Canadian Approaches to Handgun Regulation. The Journal of Law, Medicine and Ethics, 35(4), 668-678. https:// doi.org/10.1111/j.1748-720X.2007.00189.x

Wheeler, Samuel (1999). Arms as Insurance. Public Affairs Quarterly, 13(2), 111-129. 